\title{
Biodiesel unsaturation degree effects on diesel engine NOx emissions and cotton wick flame temperature
}

\author{
Mohd Fareez Edzuan Abdullah ${ }^{1, *}$, Sim Shu Zhing ${ }^{1}$, and Clarence Bilong Bugik ${ }^{1}$ \\ ${ }^{1}$ Faculty of Engineering, Universiti Malaysia Sarawak, 94300 Kota Samarahan, Sarawak, Malaysia
}

\begin{abstract}
As compared with conventional diesel fuel, biodiesel has better lubricity and lower particulate matter (PM) emissions however nitrogen oxides (NOx) emissions generally increase in biodiesel-fuelled diesel engine. Strict regulation on NOx emissions is being implemented in current Euro 6 standard and it is expected to be tighter in next standard, thus increase of NOx cannot be accepted. In this study, biodiesel unsaturation degree effects on NOx emissions are investigated. Canola, palm and coconut oils are selected as the feedstock based on their unsaturation degree. Biodiesel blends of B20 were used to fuel a single cylinder diesel engine and exhaust emissions were sampled directly at exhaust tailpipe with a flue gas analyser. Biodiesel flame temperature was measured from a cotton wick burned in simple atmospheric conditions using a thermocouple. Fourier transform infrared (FTIR) spectrometer was also used to identify the functional groups presence in the biodiesel blends. Oxygen content in biodiesel may promote complete combustion as the NOx emissions and flame temperatures were increased while the carbon monoxide (CO) emissions were decreased for all biodiesel blends. It is interesting to note that the NOx emissions and flame temperatures were directly proportional with biodiesel unsaturation degree. It might be suggested that apart from excess oxygen and free radical formation, higher NOx emissions can also be caused by the elevated flame temperatures due to the presence of double bonds in unsaturated biodiesel.
\end{abstract}

\section{Introduction}

Biodiesel is a mono-alkyl esters of fatty acids derived from vegetable oils or animal fats commonly produced by transesterification process where the triglycerides are reacted with alcohols usually methanol or ethanol in the presence of acid or base catalyst [1]. Biodiesel can reduce the dependence on petroleum-based diesel fuel where with current trend of oil consumption, half of the world total oil reserve would be depleted by 2025 [2]. Biodiesel is gaining attraction as alternative fuel because it can be used in diesel engine with only minor engine modification and the existing fuel supply infrastructure can be utilized directly [3]. Usage of biodiesel in diesel engine can reduce particulate matter (PM), carbon monoxide

* Corresponding author: amfedzuan@unimas.my 
(CO), unburned hydrocarbon (HC) and improve life-cycle of carbon dioxide (CO2) emissions compare to petroleum diesel fuel [4]. Biodiesel production researches have been progressing actively where it can even be produced efficiently from waste oil, inedible oil and algae thus the "food/space vs fuel" can be avoided [5], [6].

Despite the promising aspects of biodiesel, it is widely reported that nitrogen oxides (NOx) emissions generally increased when diesel engine is fuelled with biodiesel [7]. Call for the use of biodiesel is facing some resistance from local authorities and private users due to the lack of fundamental knowledge of biodiesel combustion mechanisms [8]. Furthermore, automotive companies are obliged to reduce NOx emissions to $0.080 \mathrm{~g} / \mathrm{km}$ in current Euro VI regulation standards, thus the increased of NOx in biodiesel case cannot be tolerated [9]. While most researchers agreed that the biodiesel increases NOx, some researchers observed that NOx emissions were unchanged or even decreased when biodiesel was used [10], [11]. Ozsecen et. al. suggested that the biodiesel NOx is a complex mechanism as it can be affected by many factors as such different physicochemical properties seem to present different combustion characteristics at different engine specifications and conditions [12].

\subsection{Biodiesel NOx emissions}

Before discussing several hypotheses of biodiesel NOx emissions, it is helpful to understand the fundamental of NOx formation. NOx is composed of mainly of nitrogen monoxide $\mathrm{NO}$ and nitrogen dioxide $\mathrm{NO} 2$. NOx is formed in high temperature conditions that mostly pronounce in burning of fossil fuel and naturally in a lightning flash. NOx formation is highly dependent on temperature where molecular nitrogen and oxygen in combustion air start to disassociate and form NOx at $1800 \mathrm{~K}$ and will exponentially increase as the temperature increase following reversible three steps Zeldovich mechanism are as follow [13].

$$
\begin{aligned}
& \mathrm{N} 2+\mathrm{O} \leftrightarrow \mathrm{NO}+\mathrm{N} \\
& \mathrm{N}+\mathrm{O} 2 \leftrightarrow \mathrm{NO}+\mathrm{O} \\
& \mathrm{N}+\mathrm{OH} \leftrightarrow \mathrm{NO}+\mathrm{H}
\end{aligned}
$$

Noted that thermal NOx mechanism is governed by gas mixture temperature and it does not has a direct relationship with fuel properties. Although biodiesel NOx emissions cannot be quantitatively determined by a single factor, yet higher in-cylinder and/ or flame temperatures and longer combustion period would most likely increase NOx formation. Some common explanations on how biodiesel increase NOx emissions are discussed as follow [14]:

1. High bulk modulus of elasticity of biodiesel propagates wave faster in the fuel pump line thus the fuel is injected earlier and combustion occurs near to high pressure/ temperature top dead centre (TDC). NOx emissions are expected to increase significantly when longer injection period is coupled with high temperature in-cylinder temperatures.

2. Oxygen content in biodiesel is suspected to promote complete combustion in diesel engine. Fuel available is expected to improve air-fuel ratio that might increase flame temperature that leads to higher NOx formation.

3. Soot particles in diesel spray flame are heated up during combustion resulting in heat loss through radiation. Low soot biodiesel combustion is expected to have higher actual gas mixtures temperature that might causes higher NOx due to radiation heat loss. 
Despite of having roughly $10 \%$ oxygen content, some authors argued that biodiesel should not produce higher actual or adiabatic flame temperature compare to the conventional diesel fuel due to it lower heating value [15]. Thus it might be considered that when biodiesel is used, there are differences in chemical kinetic pathway that form NOx other than the thermal NOx mechanism. Another NOx mechanism that is usually related to biodiesel properties (i.e. unsaturation degree) is prompt NOx or Fennimore mechanism where formation of free radicals in the flame front of hydrocarbon flames leads to rapid production of $\mathrm{NO}$ as below [16].

$$
\begin{aligned}
& \mathrm{CH}+\mathrm{N} 2 \leftrightarrow \mathrm{HCN}+\mathrm{N} \\
& \mathrm{CH} 2+\mathrm{N} 2 \leftrightarrow \mathrm{HCN}+\mathrm{NH} \\
& \mathrm{N}+\mathrm{O} 2 \leftrightarrow \mathrm{NO}+\mathrm{O} \\
& \mathrm{HCN}+\mathrm{OH} \leftrightarrow \mathrm{CN}+\mathrm{H} 2 \mathrm{O} \\
& \mathrm{CN}+\mathrm{O} 2 \leftrightarrow \mathrm{NO}+\mathrm{CO}
\end{aligned}
$$

In order to elucidate the complex biodiesel combustion mechanism, the effects of the biodiesel unsaturation degree to NOx emissions will be investigated. Canola, palm and coconut biodiesels are produced to represent high, medium and low unsaturation degree biodiesel, respectively. NOx and CO emissions are measured directly from the exhaust tailpipe, flame temperatures of each biodiesels are measure in a cotton wick test and biodiesel functional groups are confirmed from their Fourier transform infrared (FTIR) spectroscopy.

\section{Experimental setup}

A Kubota single cylinder compression ignition (CI) engine was used and it specifications are provided in Table 1 . The engine was operated under low-load condition at the speed of approximately $725 \mathrm{rpm}$ throughout the tests. Although the engine was equipped with a hydraulic dynamometer as shown in Figure 1, it performance was not investigated in the present study. Exhaust gases were sampled directly from exhaust tailpipe. Since no dilution system was employ the effects of high particulate concentrations, high vapour concentrations, high temperature and pulsating flows on emissions measurement accuracy can be expected. Nevertheless, a relatively constant reading can be monitored throughout the tests.

The diesel engine NOx and CO emissions were measured with a Testo 350-XL flue gas analyser, where measurement probe was fixed at the tailpipe for about 3 minutes and 10 readings were taken for each fuel test. After new fuel was added into the fuel tank, the engine was operated for several minutes before any measurement was made to purge out previous residual fuel in the fuel supply system.

Biodiesel was produced from base-catalysed transesterification process of domestic use grade of coconut, palm and canola oil that were selected from their saturation degree as is summarized in Table 2. Methanol and potassium hydroxide $\mathrm{KOH}$ were mixed to produce potassium methoxide using heating orbital shaker at $60^{\circ} \mathrm{C}$. Feedstock oil was mixed into potassium methoxide and stirred with a magnetic stirrer. After the mixture was settled for two days, biodiesel by-product glycerol was drained out of separatory funnel and the biodiesel was washed with warm distilled water for several times before it was dried using 
magnetic heater to avoid water contamination. Biodiesel was then seal tightly, stored in a dark container and used within 5 weeks to avoid oxidation.

To avoid fuel injector clogging, biodiesel blends were limited to $20 \mathrm{wt} \%$; this biodiesel blend of canola, palm, and coconut as well as diesel fuel is abbreviated as Ca20, Pa20, Co20 and D100, respectively. It is assumed that generally biodiesel contained approximately $10 \mathrm{wt} \%$ of oxygen content [17].

Study of flame temperature in diesel combustion is necessary to validate thermal NOx emissions. However, to conduct combustion experiment with optically accessible diesel engine required high cost and extensive technical knowledge. Thus flame temperature of each pure biodiesels in a simple cotton wick at atmospheric conditions was measured. Figure 2 depicted the experiment where the flame temperatures were measured using a type $\mathrm{K}$ thermocouple inserted inside the hottest flame region just at tip of the wick and flame thermal images were recorded with a thermographic camera (ThermaCam P65). This experiment might yield useful insight in explaining biodiesel combustion phenomena despite of its simplicity compared to complex combustion mechanism in diesel engine [18]. In this study, due to unavailability of canola biodiesel, similarly unsaturated sesame biodiesel was used.

Finally a Shimadzu IRAffinity-1 FTIR spectrometer was used to measure the spectroscopy of canola, palm and coconut biodiesel blends. From the spectroscopy one can identify any functional groups present in the fuel and might be useful to identify fuel impurities such as water contamination that can be detected at wavelength region above $3400 \mathrm{~cm}-1$.

Table 1. Diesel engine specifications.

\begin{tabular}{|l|l|}
\hline Item & Specification \\
\hline Manufacturer & Kubota Engine \\
\hline Model & RK95-1-NB-RDK \\
\hline Injection type & Direct injection \\
\hline Air intake & Naturally aspirated \\
\hline Bore $\times$ stroke $(\mathrm{mm})$ & $86 \times 84$ \\
\hline Displacement $(\mathrm{cc})$ & 487 \\
\hline Maximum output $(\mathrm{kW})$ & $7.09(2400 \mathrm{rpm})$ \\
\hline Continuos output $(\mathrm{kW})$ & $5.97(2200 \mathrm{rpm})$ \\
\hline Maximum torque $(\mathrm{kgfm})$ & $3.08(1800 \mathrm{rpm})$ \\
\hline
\end{tabular}

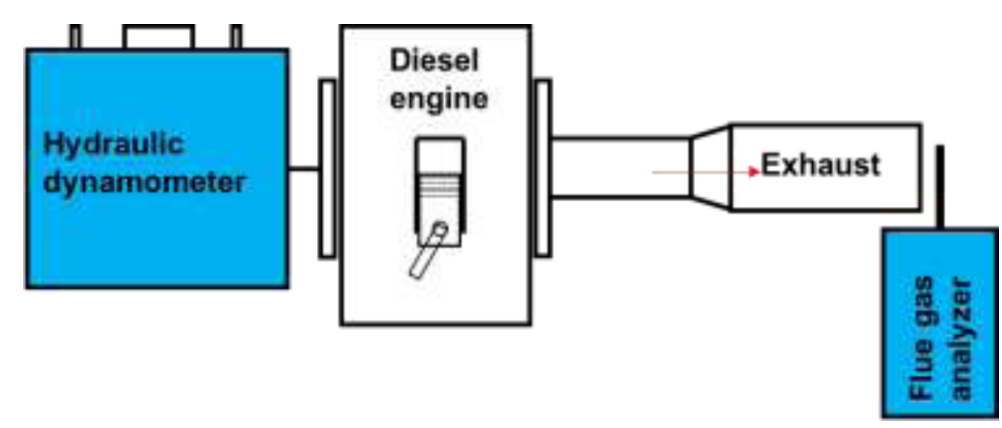

Fig. 1. Diesel engine experimental setup. 
Table 2. Properties of canola, palm and coconut biodiesel.

\begin{tabular}{|l|c|c|c|}
\hline Biodiesel & Saturation degree (wt \%) & Cetane number & Kinematic viscosity at $\mathbf{4 0}^{\circ} \mathbf{C}\left(\mathbf{m m}^{2} / \mathbf{s}\right)$ \\
\hline Canola & 7.0 & 51.6 & 4.0 \\
\hline Palm & 45.6 & 56.2 & 5.0 \\
\hline Coconut & 81.5 & 68.0 & 2.7 \\
\hline
\end{tabular}

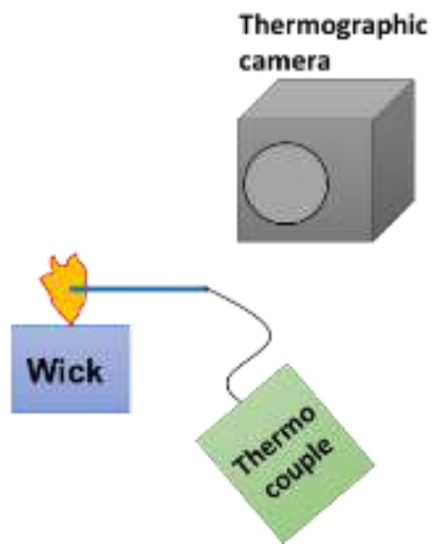

Fig. 2. Flame temperature experimental setup.

\section{Results and discussion}

\subsection{NOx and CO emissions}

Figure 3 shows NOx and CO emissions of diesel fuels and B20 blends sampled at the tailpipe where the error bars indicate standard deviation value. Figure 3(a) shows that the NOx emissions were increased in all biodiesel blends while Figure 3(b) shows that the CO emissions were decreased in all biodiesel blends. Although the oxygen content was not measured in each blend, B20 fuel (20\% biodiesel blends) contains approximately $4 \%$ of oxygen assuming that biodiesel generally contains $10 \%$ oxygen. At first glance, it would be expected that excess oxygen in biodiesel blends will promote complete combustion thus will elevate formations of NOx and suppress formation CO. However, the results in Figure 3(a) shows that the NOx emissions appear to be directly proportional with unsaturation degree where highly unsaturation canola biodiesel produce highest NOx emissions and likewise. However, $\mathrm{CO}$ emissions shown in Figure 3(b) seem to have a weak relation with biodiesel unsaturation degree.

If we reason the biodiesel NOx emissions from thermal NOx mechanism only, the NOx emissions for all biodiesels in this study would be similar since oxygen contents in all blend is approximately $4 \%$. It might be suggested that prompt NOx formation might contributed to significant portion of total NOx emission in biodiesel case considering that NOx emissions of canola biodiesel is $50 \%$ higher than coconut biodiesel. However further investigation needed to be conducted on the combustion kinetics of the biodiesel surrogate fuels with different unsaturation degree, i.e. stearic acid, oleic acid and linoleic acid. 

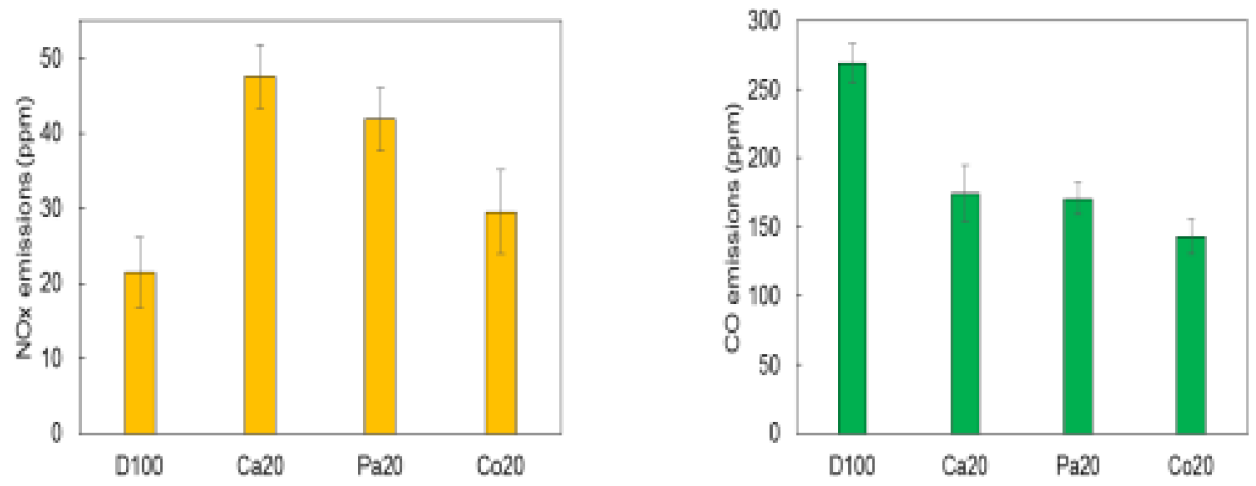

Fig. 3. NOx emissions (a) and CO emissions (b) of diesel, canola, palm and coconut biodiesel blends $(20 \%)$.

\subsection{Flame temperatures}

Figure 4 shows the flame temperature of diesel fuel, B20 and B100 in a cotton wick flame test at atmospheric conditions using a $\mathrm{K}$ type thermocouple. Sesame biodiesel was chosen to represent canola biodiesel in this test since both feedstock oils are highly unsaturated. It can be seen that the flame temperatures were elevated as the biodiesel amounts were increased from B20 to B100; although biodiesel heating value is generally $10 \%$ lesser than that of diesel fuel, the flame temperatures for all biodiesels are higher than diesel fuel with the exception for coconut biodiesel. Equating from enthalpies, Jha et. al. concluded that flame temperature does not depends solely on heating value, but it is also a function of air-fuel ratio [18]. Additionally, high radiation heat loss might occur in diesel fuel case that will decrease its actual flame temperature. Hence oxygen content in biodiesel might promote leaner combustion, which leads to higher flame temperatures.

It is noticed that the flame temperatures is directly proportional to biodiesel unsaturation degree where highest unsaturation degree of sesame biodiesel yields highest flame temperature and likewise. These results seem to be in good agreement with the thermal NOx mechanism where higher flame temperatures will produce higher the NOx emissions as shown in Figure 3(a). Pierre-Alexandre et. al. THERGAS software calculation also showed that adiabatic flame temperatures increased when unsaturated bonds were present in the molecule [19]. However further study on how biodiesel unsaturation degree effects the temperature of actual diesel combustion can provide useful insight of the biodiesel NOx mechanism.

Figure 5 shows the variation of the flame thermal images of canola, palm and coconut biodiesel captured using a thermographic camera where the red colour and blue colour indicates maximum and minimum temperature, respectively. However the results of significantly low maximum flame temperatures and indistinctive flame shapes might be caused by the camera error. 


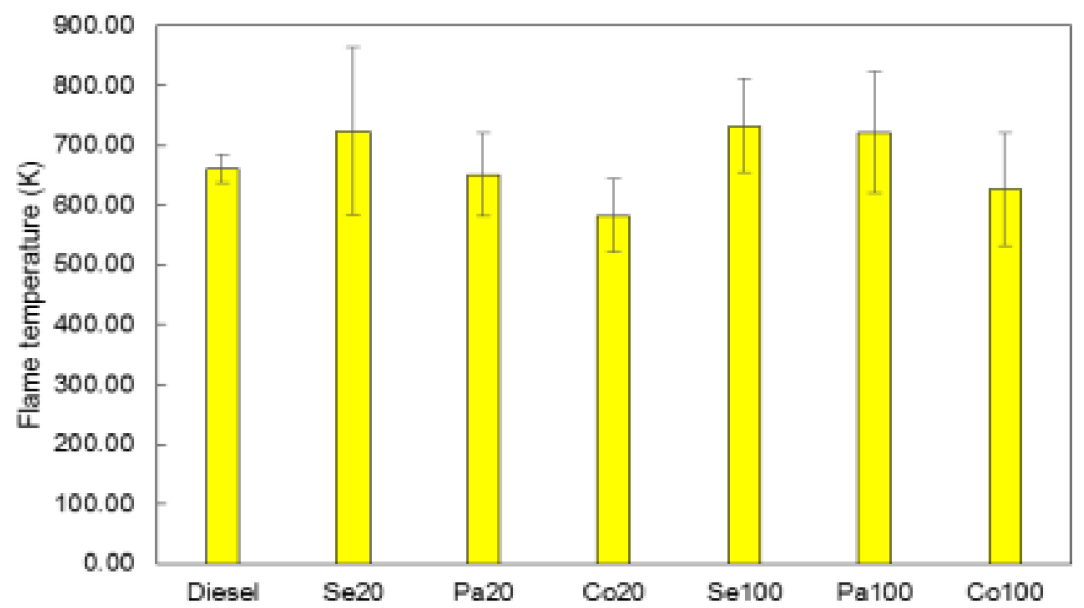

Fig. 4. Flame temperatures of diesel, sesame, palm and coconut biodiesel (canola biodiesel is substituted with similar saturation degree of sesame biodiesel).

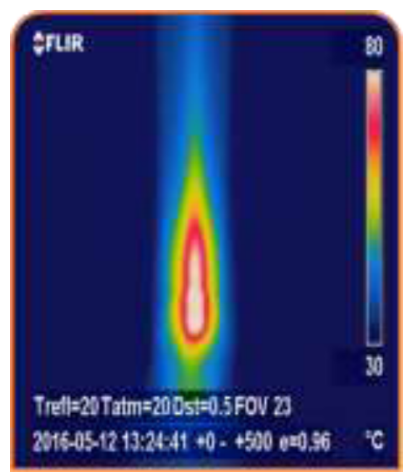

(a)

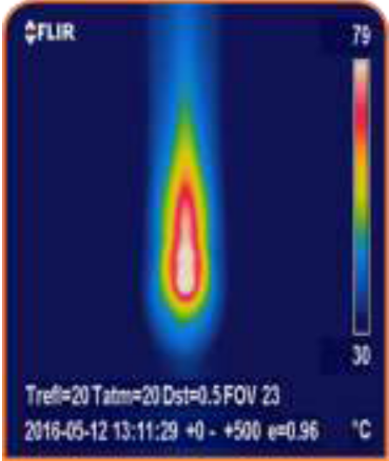

(b)

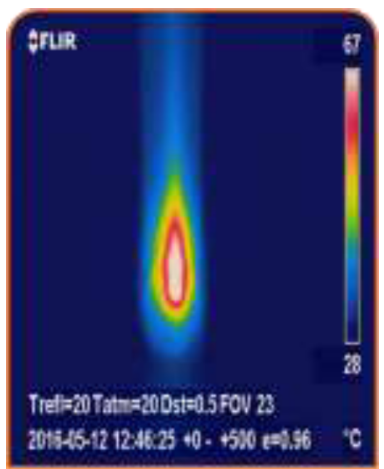

(c)

Fig. 5. Flame thermal images of canola (a), palm (b) and coconut (c) biodiesel.

\subsection{FTIR spectroscopy}

The spectrometer used in this study can only detects the presence of functional groups but cannot be used to measure quantitative property. Hence the results of all biodiesel blends used in this study are similar and can be represented by any blends. Figure 6 shows the FTIR spectroscopy of canola biodiesel blends and the peak wavelengths were indicated with red circles. Oxygen group presence was detected at $1745 \mathrm{~cm}-1$ region and no water contamination was detected at region above $3400 \mathrm{~cm}-1$ that confirm the quality of the biodiesels being produced to a certain extent. 


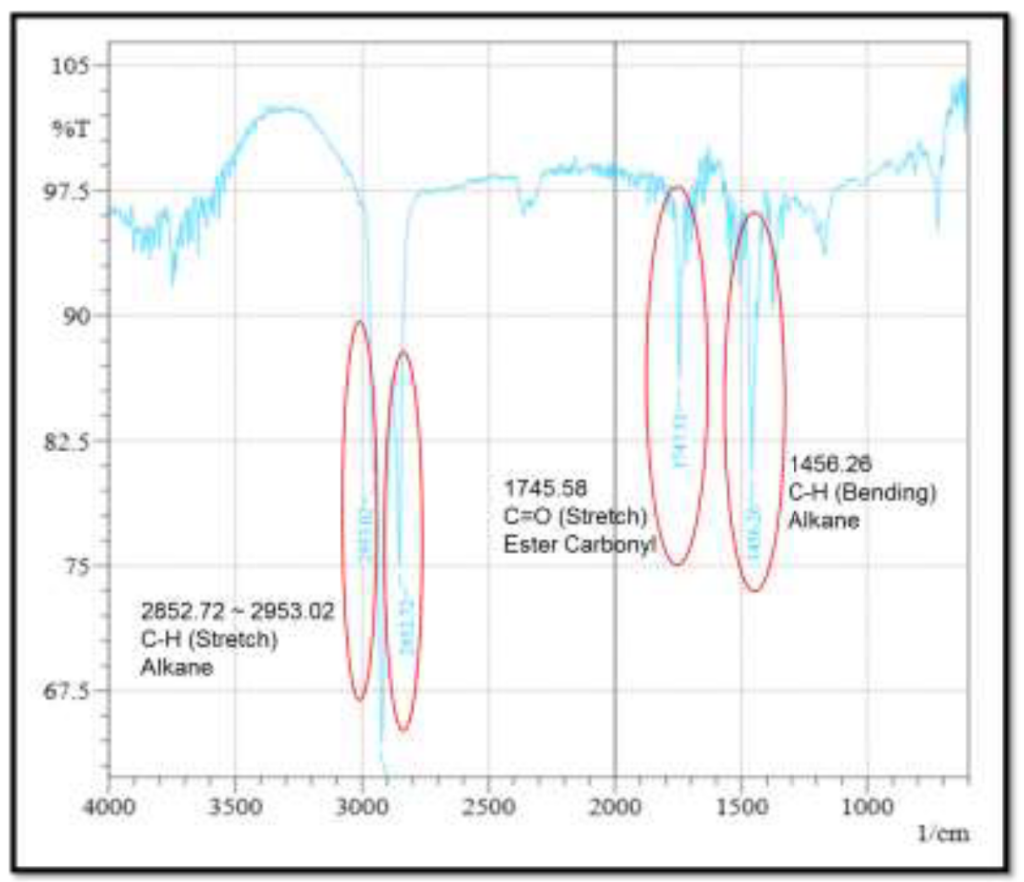

Fig. 6. FTIR spectroscopy of canola biodiesel (FTIR spectroscopy for palm and coconut biodiesel is similar).

\section{Conclusions}

In this study, it was attempted to understand the fundamental knowledge on biodiesel unsaturation degree effects on NOx emissions. Canola, palm and coconut oils were selected based on their unsaturation degree and converted to biodiesel by transesterification process. The tailpipe emissions and cotton wick flame temperature were measured and the results can be summarized as follow. NOx emissions and flame temperatures increased while CO emissions decreased in biodiesel cases compared to petroleum diesel fuel. Furthermore, the biodiesel unsaturation degree is directly proportional to NOx emissions and flame temperatures. It can be suggested that apart from the prompt NOx, the thermal NOx might also be significant for total NOx formation in highly unsaturated biodiesel case. In near future, the effects of biodiesel unsaturation degree on actual diesel combustion temperature and combustion kinetics will be investigated.

This work is supported by UNIMAS SGS grant, F02(S178)/1322/2016(2). The authors fully acknowledged Universiti Malaysia Sarawak for the approved fund which makes this research viable and the Department of Mechanical \& Manufacturing technical staff.

\section{References}

1. S. K. Hoekman and C. Robbins, "Review of the effects of biodiesel on NOx emissions," Fuel Process. Technol., vol. 96, pp. 237-249 (2012)

2. S. Fernando, C. Hall, and S. Jha, "NO x Reduction from Biodiesel Fuels," Energy \& Fuels, vol. 20, no. x, pp. 376-382 (2006) 
3. T. Aizawa, M. F. E. Bin Abdullah, A. Inoue, Y. Ishidzuka, N. Taki, and H. Kosaka, "Aromatic additive effects on soot formation in a fischer-tropsch diesel (FTD) spray flame via laser spectroscopy," Proc. 8th Int. Conf. Model. Diagnostics Adv. Engine Syst. COMODIA 2012, pp. 275-280 (2012)

4. S. M. Palash, M. A. Kalam, H. H. Masjuki, B. M. Masum, I. M. Rizwanul Fattah, and M. Mofijur, "Impacts of biodiesel combustion on NOx emissions and their reduction approaches,” Renew. Sustain. Energy Rev., vol. 23, no. 4, pp. 473-490, (2013)

5. S. Ismail, A. S. Ahmed, R. Anr, and S. Hamdan, "Biodiesel Production from Castor Oil by Using Calcium Oxide Derived from Mud Clam Shell," J. Renew. Energy, vol. 2016, p. 8 (2016)

6. T. M. Mata, A. A. Martins, and N. S. Caetano, "Microalgae for biodiesel production and other applications: A review," Renew. Sustain. Energy Rev., vol. 14, no. 1, pp. 217-232 (2010)

7. M. F. E. bin Abdullah, M. H. bin Sulaiman, and N. A. B. Abdul Majid, "NOx Emission of Diesel Fuel Blended with Different Saturation Degrees of Biofuel and with Oxygenator," Appl. Mech. Mater., vol. 660, pp. 397-401 (2014)

8. M. Lapuerta, O. Armas, and J. Rodríguez-Fernández, "Effect of biodiesel fuels on diesel engine emissions,” Prog. Energy Combust. Sci., vol. 34, no. 2, pp. 198-223, (2008)

9. European Parliament and Council of the European Union, "REGULATION (EC) No 715/2007 OF THE EUROPEAN PARLIAMENT AND OF THE COUNCIL of 20 June 2007 on type approval of motor vehicles with respect to emissions from light passenger and commercial vehicles (Euro 5 and Euro 6) and on access to vehicle repair and mai," Off. J. Eur. Union, vol. L171, no. December 2006, pp. 1-16 (2007)

10. M. N. Nabi, "Theoretical investigation of engine thermal efficiency, adiabatic flame temperature, NOx emission and combustion-related parameters for different oxygenated fuels," Appl. Therm. Eng., vol. 30, no. 8-9, pp. 839-844 (2010)

11.E. Sendzikiene, V. Makareviciene, and P. Janulis, "Influence of fuel oxygen content on diesel engine exhaust emissions," Renew. Energy, vol. 31, no. 15, pp. 2505-2512 (2006)

12.N. Ozsezen, M. Canakci, A. Turkcan, and C. Sayin, "Performance and combustion characteristics of a DI diesel engine fueled with waste palm oil and canola oil methyl esters," Fuel, vol. 88, no. 4, pp. 629-636 (2009)

13. J. Sun, J. A. Caton, and T. J. Jacobs, "Oxides of nitrogen emissions from biodieselfuelled diesel engines," Prog. Energy Combust. Sci., vol. 36, no. 6, pp. 677-695 (2010)

14.J. Mueller, A. L. Boehman, and G. C. Martin, "An Experimental Investigation of the Origin of Increased NOx Emissions When Fueling a Heavy-Duty Compression-Ignition Engine with Soy Biodiesel," SAE Int. J. Fuels Lubr., vol. 2, no. 1, pp. 789-816 (2009)

15. M. Lapuerta, O. Armas, R. Ballesteros, and J. Fernández, "Diesel emissions from biofuels derived from Spanish potential vegetable oils," Fuel, vol. 84, no. 6 SPEC. ISS., pp. 773-780 (2005)

16. Fenimore, "Formation of nitric oxide in premixed hydrocarbon flames," Symp. Combust., vol. 13, no. 1, pp. 373-380 (1971)

17.K. Varatharajan and M. Cheralathan, "Influence of fuel properties and composition on NO x emissions from biodiesel powered diesel engines: A review," Renew. Sustain. Energy Rev., vol. 16, no. 6, pp. 3702-3710 (2012)

18. K. Jha, S. Fernando, and S. D. F. To, "Flame temperature analysis of biodiesel blends and components," Fuel, vol. 87, no. x, pp. 1982-1988 (2008)

19.P. A. Glaude, R. Fournet, R. Bounaceur, and M. Molière, "Adiabatic flame temperature from biofuels and fossil fuels and derived effect on NOx emissions," Fuel Process. Technol., vol. 91, no. 2, pp. 229-235 (2010) 